ISIDORIANUM 24/47-48 (2015) 73-88

\title{
LECTIO DIVINA
}

\section{De la lectura al encuentro}

\author{
Álvaro Pereira Delgado \\ Centro de Estudios Teológicos - Sevilla \\ "Todo el daño que le viene al mundo es \\ de no conocer las verdades de la Escritura con clara verdad" \\ (SANTA TeResa de Jesús, Libro de la Vida, 40.1; \\ Obras compl. Monte Carmelo, p. 428)
}

Este ensayo pretende ser un sincero tributo a nuestro querido magister, don José Arturo Domínguez Asensio, mentor de la mayoría de los profesores que actualmente impartimos docencia en el CET de Sevilla. Él nos ha enseñado no solo profundas verdades teológicas e indispensables intuiciones metodológicas sino una forma de vivir, pensar y servir propia de un sacerdote diocesano que pastorea con la noble arma de la inteligencia. Con uno de sus audaces e ingeniosos adagios — "el que lea que entienda" (Mc 13,14)— nos solía incitar a la lectura de la Sagrada Escritura. Nos proponía además que dicha lectura debía ser iluminada por la tradición viva de la Iglesia. En fin, también admiro en nuestro querido profesor su continuo esfuerzo por la sintesis, la verdad de Dios solo puede conducir hacia la unidad. Tomando prestadas estas tres intuiciones de don José Arturo -lectura de la Escritura, importancia de la tradición y voluntad de síntesis - presento a continuación un sencillo ensayo 
sobre la lectio divina que no pretende proponer nuevas teorias, ni entrar en pormenores de escuela, sino que es simplemente una excusa para meditar sobre la lectura creyente de la Palabra inspirada, a la luz de la tradición patrística y eclesial. En un primer momento realizaremos una meditación histórica sobre el tema y posteriormente propondremos un itinerario metodológico sobre la lectura creyente de la Escritura. Comencemos.

Decía san Gregorio Magno a propósito de Ez 1,19-21 que "las palabras divinas crecen con el que las lee" ("divina eloquia cum legente crescunt»: Hom. sobre Ezequiel, 1.7.8; CCL 142, 87; BAC 170, pp. 299-300). Ciertamente, en la lectura creyente de la Palabra de Dios, tanto el lector como la Escritura crecen. El lector crece no solo porque aumenta su saber sobre Dios sino porque va renovándose hasta alcanzar la altura del hombre perfecto, la plena madurez en Cristo (Ef 4,13). Y la Sagrada Escritura también crece no solo porque cada lector en su circunstancia especifica alumbra significados y aplicaciones nuevas del manantial inagotable de la Escritura, sino porque la Palabra, en tanto que es el Verbo de Dios diciéndose a los hombres, sigue formándose en ellos (Gál 4,19), sigue completando en ellos su pasión $(\mathrm{Col} 1$,24) y sigue acompañándolos hasta el final del mundo (Mt 28,20). Si bien toda la verdad de Dios ya ha sido comunicada en las Escrituras y no debemos esperar nuevas revelaciones (cf. Verbum Domini, 14), el diálogo de amor continúa: "Dios que habló en otros tiempos, sigue conversando siempre con la Esposa de su Hijo amado" (Dei Verbum, 8). Y la lectura creyente de la Escritura es la vía indispensable para discernir el sentido de este diálogo continuo.

Tomamos como punto de partida la definición de lectio divina que propuso la Pontificia Comisión Bíblica: "La Lectio Divina es una lectura individual o comunitaria de un pasaje de la Escritura, acogida como Palabra de Dios, y que se desarrolla bajo la moción del Espíritu en meditación, oración y contemplación" (La interpretación de la Biblia en la Iglesia, Roma 1993, p. 114). Entendida así, no se debería considerar la lectio divina como otro útil método de oración, o como una práctica devocional más, al mismo nivel que el rosario, el via crucis o las hagiografias. La lectura creyente de la Escritura va transformando al que la lee y 
es el medio indispensable para dialogar con Dios: «a Él hablamos cuando oramos, y a Él oímos cuando leemos las palabras divinas" (san Ambrosio, Sobre los oficios de los ministros, 1.20.88; CCL 15, 33; citado en Dei Verbum, 25). Benedicto XVI subrayó esta idea de la lectura al encuentro- en la Verbum Domini: "La lectio divina es verdaderamente capaz de abrir al fiel no sólo el tesoro de la Palabra de Dios sino también de crear el encuentro con Cristo, Palabra divina y viviente... La lectura de la Palabra de Dios nos ayuda en el camino de penitencia y conversión, nos permite profundizar en el sentido de la pertenencia eclesial y nos sustenta en una familiaridad más grande con Dios" ( $\left.n^{\circ} 87\right)$.

Por ello, tanto los santos padres como el Concilio han situado la lectura de la Escritura - una lectura creyente actualizada en la liturgia- al mismo nivel que la participación en el cuerpo eucarístico de Cristo (cf. Dei Verbum, 21). Muy ilustrativas, en este sentido, son las palabras de san Jerónimo: "La carne del Señor es verdadera comida y su Sangre es verdadera bebida (cf. Jn 5,56), en este mundo sólo tenemos este único bien, comer su Carne y beber su Sangre, no sólo en el misterio, sino también en la lectura de las Escrituras. Efectivamente, verdadera comida y bebida, tomada de la Palabra de Dios, es la ciencia de las Escrituras (san JERÓNIMO, Com. al Eclesiastés 3.12-13; PL 23, 1039A; Biblioteca Patrística 64, p. 93). Las dos mesas, la mesa de la Palabra y la mesa de la Eucaristía, son en realidad una misma: Cristo dándose al creyente que escucha y participa de Él.

\section{ORÍGENES DE LA LECTURA CREYENTE DE LA ESCRITURA}

La Biblia no nació como una obra uniforme en la que se fueron escribiendo los diferentes capítulos sucesivamente, sino que experiencias históricas, relatos legendarios, composiciones literarias $\mathrm{y}$ personajes modélicos fueron siendo recordados, actualizados y reescritos en diferentes épocas, de múltiples modos y con diversos objetivos, hasta conformar una obra coral en contante dinamismo. Las historias antiguas fueron releídas en las nuevas circunstancias hasta dar de sí nuevos escritos. Por ejemplo, Sab 11,2-19,22 es una relectura de los relatos del Éxodo para las circunstancias de una comunidad, judíos de la diáspora egipcia, que allá por el siglo I a.C. volvieron a tener tentaciones parecidas al pueblo en edades 
pretéritas: perder su identidad israelita y adorar a los idolos. Releyendo la experiencia del Éxodo, en este caso en griego, el autor sagrado les recuerda que ellos pertenecen al pueblo elegido. Aunque vivan en tierra extraña, no deben olvidar quiénes son.

No solo el Antiguo Testamento atestigua un proceso continuo de relecturas sucesivas de tradiciones antiguas. Se podría decir que el Nuevo Testamento es, en su conjunto, una relectura creativa del Antiguo a partir de la novedad cimera de Jesucristo. Esta novedad no era reconocible aún en las palabras antiguas por sí solas, pero dichas palabras antiguas "alcanzan su pleno significado a través del evento en el que ellas se hacen realidad" (BENEDICTO XVI, La infancia de Jesús, Madrid 2012, p. 22).Así pues, las Escrituras de Israel son profecía divina cumplida escatológicamente en el Mesias Jesús y en su comunidad mesiánica. El sentido último de las Escrituras, por tanto, no reside en su origen histórico, en la intención que los autores humanos de cada libro quisieron transmitir, sino en su fin escatológico, la verdad cimera revelada en Cristo. Así lo confirma san Pablo a propósito de lo sucedido a Israel en el desierto: "Todo esto les acontecía en figura, y fue escrito para aviso de los que hemos llegado a la plenitud de los tiempos" (1 Cor 10,11; cf. 2 Cor 1,1820; 3,14; etc.). Por ello, Jesucristo muerto y resucitado es la clave interpretativa básica para comprender las Escrituras. Notemos en este sentido la inmejorable formulación de san Buenaventura: "Del conocimiento de Jesucristo, como de su principio original, dimana la firmeza y la inteligencia de toda la Sagrada Escritura. Por donde es imposible que ninguno entre a conocerla si antes no tuviere infusa en sí la fe de Cristo como lámpara, puerta y fundamento de toda la Escritura" (Breviloquio. Prólogo 2; BAC compl. Tomo I, p. 167). Así pues, no son solo las Escrituras las que conducen a Cristo, sino que es el encuentro con Cristo el que esclarece el sentido de las Escrituras. Por ello Origenes puede llegar a afirmar que, gracias a Cristo, toda la Escritura, Antiguo y Nuevo Testamento, se convierte en evangelio: "La ley y los profetas, siendo anteriores a la venida de Cristo, no contenian el anuncio de que habla la definición de evangelio, en cuanto que aún no había llegado aquel que aclara los misterios contenidos en ellos. Pero el Salvador, en la medida en que ha venido y ha realizado la encarnación del evangelio, con el evangelio lo ha convertido todo, por asi decirlo, en evangelio" (Orígents, Sobre el evangelio de Juan, 1.6.33; SC 120bis, 74). 
Este contante proceso de relectura al interior de la Biblia continuó con los primeros cristianos, que acogieron los textos como escritos autorizados. Las primeras comunidades siguieron haciendo aquello que aprendieron de los autores sagrados. Los santos padres y las generaciones sucesivas releyeron sus vicisitudes a la luz de la Escritura. Y es que los padres no comentaban los textos, sino que más bien interpretaban su realidad a la luz de los textos (cf. M. Mitchell, Paul, the Corinthians and the Birth of the Christian Hermeneutics, Cambridge - New York 2010, p. 106). La Escritura no era solo el objeto de su estudio, sino la clave de lectura o el foco a través del cual entenderlo todo gracias a la iluminación divina. Del mismo modo, el creyente de hoy está llamado a cambiar de óptica e interpretar toda su realidad con la nueva luz que le ofrece la Escritura. Y la lectio divina, gracias a la asistencia del Espíritu Santo, se revela como el mejor modo para realizar dicha empresa del espíritu.

\subsection{La lectura creyente de los santos padres}

La interpretación bíblica de los santos padres es un tema amplio, fascinante y complejo. Solo nos acercamos a él en tanto que nos ayuda a comprender cómo la lectura espiritual de la Escritura se fue enriqueciendo en aquella época fundante. Los padres continuaron el proceso de relectura de la Escritura gestado ya al interior de la misma Biblia y lo enriquecieron con los métodos exegéticos rabínicos y con las lecturas alegóricas que los griegos hacían de sus textos fundacionales (Odisea e Ilíada). En este sentido, el proceder alegórico del judío helenista Filón de Alejandría influyó mucho en los padres alejandrinos (Clemente, Orígenes) y, a través de ellos, en el resto de la teología cristiana.

En polémica con la herejía marcionita y con las interpretaciones gnósticas, muchos padres de la Iglesia (Ireneo, Clemente, Orígenes, Tertuliano) subrayaron la unidad de los dos testamentos. El Antiguo Testamento no era obra de un dios menor, sino que debía ser leído como un texto inspirado. Al leer la Escritura, por tanto, los padres intentaron evidenciar la "connaturalidad" (syggeneia) entre los personajes y eventos del Antiguo y del Nuevo Testamento, captar cómo Dios había profetizado, prefigurado y cumplido en Cristo y 
su Iglesia lo dicho en generaciones precedentes. En esta búsqueda, los padres compartian un principio fundamental: la presencia de un segundo significado, más allá del literal, en las Escrituras inspiradas. Este significado no era arbitrario sino, muy al contrario, era la manera que Dios tenía para seguir comunicándose con su esposa, la Iglesia. Dicha convicción hacía que siempre se debiera escrutar la Palabra para atisbar el misterio escondido: "factum audivimus, mysterium inquiramus" ("oímos el hecho, indagamos el misterio": dicho atribuido a san Gregorio Magno). Esta voluntad de profundización constante se dio en llamar posteriormente la "lectura espiritual" de la Escritura (Pedro Damián), la lectio sacrae paginae (Abelardo, Pedro Lombardo, San Tomás de Aquino) o la lectio divina, que recoge la rica tradición patrística antigua y monástica medieval.

A mediados del siglo XX, los dos grandes patrólogos Danielou y Henri de Lubac debatieron sobre el método fundamental que tenían los padres al leer la Escritura. Danielou prefería la "lectura tipológica" (lectura más propiamente antioquena), mientras que de Lubac optaba por la "lectura alegórica" (más propiamente alejandrina) o "lectura espiritual». Quizás lo mejor sea reparar en las dos aproximaciones al texto inspirado para no perder la riqueza de cada acercamiento. No nos fijamos tanto en las ideas de cada autor, cuanto en una síntesis que nos sirva a la hora de leer los textos (sigo aquí a G. I. Gargano, La lectio divina nella vita dei credenti, Torino 2008, pp. 27-36):

- El modelo tipológico. El lector debe reparar, en primer lugar, en el significado literal del texto, es decir, la intención del autor humano al plasmar sus ideas. Por ejemplo, el sentido literal de Gén 1 consiste en la convicción de que todo lo que existe proviene de la acción creadora de Dios. Ahora bien, es necesario distinguir entre sentido literal y literalismo: el sentido literal de Gén 1 no implica leer el pasaje como una estricta crónica histórica ("asî pasó, en siete días") sino en comprender su género literario y escrutar a través de él las circunstancias e intención del autor. En segundo lugar, el lector debe buscar el significado tipológico del texto, es decir, aquel sentido que Dios quiso albergar en el texto, quizás desconocido por el autor humano, y que 
apunta al cumplimiento del pasaje en el misterio de Cristo. Continuando con el ejemplo de la creación, la relación tipológica entre Gén 1,1 ("En el principio creó Dios los cielos y la tierra") y Jn 1,1 ("En el principio existía la Palabra") muestra que Dios creó el mundo por medio de su Palabra, Jesucristo el Señor. Así pues, el texto del autor humano es profecia, figura, sombra o prefiguración del significado pretendido por el autor divino. Otros ejemplos de tipologias: Mt 1,22-25 identifica en el nacimiento virginal de Jesús el cumplimiento de la profecía de Is 7,14 ("la virgen concebirá y dará a luz un hijo") o el arca de Noé (Gén 7) es releído en 1 Pe 3,20-21 como prefiguración del bautismo. La lectura tipológica toma en serio las dos historias y cree que Dios actuó y actúa prefigurando el futuro en el pasado, y revelando el verdadero significado del pasado en el futuro. El lector entiende que cada evento es un eslabón de la gran cadena de la historia que Dios va trazando providencialmente y que tiene como eje a Cristo y a su Iglesia. Y el mismo fiel, finalmente, se siente eslabón gozoso de dicha cadena. Por eso, cada cristiano puede leer legitimamente que sus sufrimientos y alegrias, su experiencia vocacional, su vivencia de los sacramentos o su lucha contra el pecado están ya prefigurados e iluminados en las paginas sagradas de la Escritura.

- El modelo alegórico. El modelo alegórico es semejante al anterior pero incide no tanto en el cumplimiento histórico del Antiguo Testamento en el Nuevo (movimiento horizontal), cuanto en el ascenso desde el sentido carnal y terrenal hacia las alturas de los significados divinos (movimiento vertical). Es indispensable, para ello, que Cristo sea el interprete de los textos. Él desentrañará los misterios divinos si el lector se adhiere a él. El conocimiento, una vez más, se produce por connaturalidad: mientras más se una uno a Cristo más lo comprenderá todo con sus criterios e irá desentrañando los misterios del Espíritu encerrados en la letra del texto. Para entender a Cristo es necesario identificarse con Cristo. La lectura alegórica es, por tanto, una especie de pascua o bautismo: Cristo transforma nuestro modo de leer las Escritura hasta reconocerlo siempre en todas ellas. 


\begin{abstract}
Siguiendo la senda abierta por el modelo alegórico, surgió en la Edad Media el esquema de los cuatro sentidos. Por su carácter sintético reproducimos el famoso dístico de Agustín de Dacia (1282): "littera gesta docet quid credas allegoria, moralis quid agas quo tendas anagogia" ("el sentido literal enseña los hechos, la alegoría lo que debes creer, el sentido moral lo que tienes que hacer, y la anagogía a lo que debes tender": Rotulus pugillaris, I; ed. A. WALz, Angelicum 6 [1929] p. 256; citado en CEC 118). Los cuatro sentidos se relacionan de forma dinámica: sin el sentido literal el texto bíblico no tendría raigambre histórica, por eso no se puede despreciar. El sentido alegórico relee hechos y palabras a la luz del misterio de Cristo. El sentido moral subraya la influencia de la lectio divina en la vida y conducta moral del creyente, de la Iglesia y del mundo. La Escritura invita a la conversión y a la transformación de la realidad. Y finalmente la lectio divina del texto inspirado llena al lector creyente de esperanza en el cielo y lo impulsa hacia las alturas divinas.
\end{abstract}

\title{
1.2. La carne, el alma y el espiritu de la Escritura (Origenes de Alejandria)
}

Nos detenemos a continuación en una iluminadora propuesta de Origenes de Alejandría que nos servirá de guía para nuestro modo de presentar la lectio divina. Él emplea una analogía antropológica. La Escritura tiene cuerpo, alma y espíritu (soma, psiché, pneuma), como el ser humano (cf. 1 Tes 5,23); así pues el lector debe ir conociendo y comprendiendo cada una de estas dimensiones para penetrar los misterio que la Escritura encierra. La analogía no es extraña a la esencia del texto: si la Escritura alberga la Palabra de Dios, y la Palabra de Dios es Cristo, el creyente debe relacionarse con la Escritura como con una persona semejante a él. Es posible que Orígenes tomara esta analogía de los gnósticos, que dividian a los creyentes en tres razas: los carnales, los psíquicos y los espirituales. Pero para Orígenes estos tres estadios no eran tres naturalezas fijas e infranqueables, sino una dinámica de progreso y ascenso, en el que el creyente debía ir escalando peldaños desde lecturas más carnales y literales hacia los significados espirituales y divinos. Así dice Orígenes: 
Entonces, este nos parece el método con que se debe leer las Escrituras y acoger su sentido: el que está delineado por los mismos oráculos. En Salomón, en Proverbios, encontramos un cierto precepto acerca de las doctrinas de los escritos divinos: $Y$ tú, inscribe esto tres veces en la voluntad y en el conocimiento, para responder palabras verdaderas a los que te aborden (Prov 22,20-21). Por lo tanto, se requiere inscribir tres veces en la propia alma los sentidos de las santas Escrituras. De modo que, el demasiado simple se beneficie, por así decirlo, de la carne de la Escritura (de esta manera llamamos a la interpretación inmediata); el que ha ascendido un poco [se beneficie] de algo así como del alma de la [Escritura]; y el perfecto [se beneficie] de la ley espiritual, que contiene una sombra de los bienes futuros, el cual es semejante a aquellos a los que el Apóstol dice: Pero hablamos una sabiduría entre los perfectos, pero no la sabiduria de este siglo, ni de los perecederos príncipes de este siglo, sino que hablamos la sabiduria de Dios, escondida en el misterio, la que Dios ha predestinado antes de los siglos para nuestra gloria (1 Cor 2,6-7). Pues bien, tal como el hombre está compuesto de cuerpo, alma y espiritu, del mismo modo también la Escritura que Dios ha dispuesto conceder para la salvación de los hombres (Orígenes, Sobre los principios, 4.2.4; Fuentes Patrística 27, pp. 841-843).

Para Orígenes, el sentido somático es el literal, la información histórica sobre la acción de Dios entre los hombres y la enseñanza moral concreta sobre preceptos, ejemplos y virtudes a perseguir. El sentido anímico o psíquico es un sentido ya no literal, es una lectura figurativa del texto que conduce al lector a imitar a Cristo y así crecer como persona. El sentido pneumático o espiritual, finalmente, ilumina al lector y le revela el plan de salvación que Dios ha llevado acabo en él a través de Cristo y de su Iglesia con la vista puesta en el futuro escatológico (cf. E. Dively LAURo, The Soul and Spirit of Scripture within Origen's Exegesis, Leiden 2005, pp. 2-3). Iluminados por estas ideas de Orígenes, proponemos un itinerario metodológico para desarrollar la lectio divina.

\section{EL PROCESO DE LA LECTURA ESPIRITUAL. UN ITINERARIO PARA LA LECTIO DIVINA}

Antes de comenzar, san Juan Crisóstomo da una buena recomendación: "Cuando tomamos en nuestras manos el libro espiritual, hemos de poner en vela nuestro espíritu, recoger nuestros pensamientos, echar fuera cualquier preocupación 
terrena. Dediquémonos entonces a la lectura con mucha devoción, con gran atención, para que se nos conceda que el Espíritu Santo nos guie a la comprensión de lo que está escrito y recibamos de ello mucho beneficio" (Homilias al Génesis, 35.1; PG 53, 321-322).

El creyente debe seguidamente leer y reconocer la carne de la Escritura, es decir la materialidad del texto. Para conocer al Cristo de Dios es necesario reparar en el hombre Jesús. El lector debe perseguir primero el sentido literal para evitar moralismos, espiritualismos o fundamentalismos. Fieles a esta convicción, los monjes transcribian, memorizaban, traducian y estudiaban los textos. Así mismo el lector actual debe estudiar concienzudamente el texto en sus pormenores históricos y literarios: ¿cuándo y en qué circunstancias se escribió? ¿cuál fue la intención de su autor? ¿qué otros textos lo iluminan? Todos los procedimientos de la exégesis científica encuentran aquí cabida. Acoger la carne de la Escritura es aceptar el misterio de la encarnación. Si el Hijo de Dios se ha hecho hijo del hombre, también la Palabra de Dios se ha hecho palabra de hombre, por su condescendencia divina (cf. Dei Verbum, 13). Para no hacer decir a la Palabra divina aquellos que nosotros queramos que ella diga y para evitar espiritualismos arbitrarios o integrismos peligrosos, el lector debe aceptar la objetividad de la Escritura, su carne. El texto es la instancia objetiva indispensable que nos sirve de punto de partida en nuestra escucha de la voz divina. De nuevo recurrimos a las finas intuiciones de san Buenaventura: "Así como el que se desdeña de aprender los primeros elementos de que se compone la dicción nunca puede conocer ni el significado de las dicciones ni la recta ley de las construcciones, del mismo modo el que desprecia o descuida la letra de la Sagrada Escritura nunca se elevará a sus sentidos espirituales" (Breviloquio. Prólogo 6.1; BAC Obras compl. Tomo I, p. 191).

Aceptar la carne de la Escritura implica asumir lo que los padres del desierto llamaban la pugna daemonum (cf. Gargano, Lectio divina, pp. 40-42), es decir, educar la propia atención del corazón y de la mente para liberarnos de nuestras pasiones y dejar que todo nuestro ser se centre en la escucha de la Palabra. "En efecto, la palabra sólo puede ser pronunciada y oída en el silencio, exterior e interior... La gran tradición patrística nos enseña que los misterios de Cristo están unidos al silencio (Cf. san Ignacio DE AnTioquía, 
Epístola a los Efesios, 15.2; Fuentes Patrísticas 1, p. 119), y sólo en él la Palabra puede encontrar morada en nosotros, como ocurrió en María, mujer de la Palabra y del silencio inseparablemente" (Verbum Domini, 66). Leer la Escritura implica no solo el silencio orante, sino también una necesaria ascesis en la que el fiel domina sus instintos, y a través de la vigilia y del ayuno se centra en Dios, sin caer, lógicamente, en extremismos ni dualismos. No se trata de quitarle al cuerpo lo que necesita, sino de orientarlo a la escucha de la Palabra. Una de estas pasiones, según los santos padres, era la herejía. No puede comprender la Escritura aquel que fractura la comunidad eclesial. La lectio divina implica humildad y aceptación del discernimiento eclesial. El orante honesto sabe que el criterio último de discernimiento no puede estar en él sino que le viene dado. Por eso san Agustín llega a decir: "No creería en el Evangelio, si no me moviera a ello la autoridad de la Iglesia católica" (Contra la epistola de los Maniqueos que llaman fundamentos 5.6; PL 42, 176; cf. CEC 119).

Tras acoger la carne de la Palabra es preciso reconocer su "alma" (psiqué), que también puede ser traducido como su "vida". Y es que la Biblia no es un libro muerto, no es un cadáver que diseccionar, sino un organismo vivo plagado de conexiones. El lector jamás debe creer dominar un texto, sino convertirse en su interlocutor. Los monjes medievales ahondaron en esta "vitalidad" de la Escritura cuando practicaban la collatio. La collatio consiste en la "recolección" de otros textos que guardan relación con el que estamos leyendo. Puesto que la Escritura es un organismo vivo dotado de unidad, es pertinente sondear sus interrelaciones. A tal fin es necesario identificar los paralelos del texto, ir saltando de texto en texto como la araña que va tejiendo su tela. Dichas conexiones no solo se dan entre textos homogéneos, sino que también deben ser establecidas entre el Antiguo y el Nuevo Testamento, según el famoso adagio de San Agustín: "novum in vetere latet et in novo vetus patet" ("el Nuevo en el Antiguo late y el Antiguo en el Nuevo se hace patenten: san Agustín, Cuestiones sobre el Heptateuco, 2.73; PL 34, 623; cf. DV 16). En esta búsqueda de textos el lector debe emplear su inteligencia y echar mano de comentarios u otros subsidios para que las asociaciones no sean arbitrarias o fantasiosas. Caer en un exceso de alegorismo o en una lectura piadosa y moralista que no tiene nada que ver con el sentido literal del pasaje es despreciar la 
carne del texto. Ya Santo Tomás advertía: "omnes sensus (sacrae Scripturae) fundentur super unum litteralem sensum" ("todos los sentidos de la Sagrada Escritura se fundan sobre el literal»: Summa Theologica 1 q.1, a.10, ad 1; cf. CEC 116).

Tras leer (lectio)y recoger (collatio) qué dicen los textos, el creyente se pregunta qué le dicen a él y qué le dicen de él (meditatio). Ahora bien, esta sucesión de pasos no es lineal. Todo lector orante sabe que los diferentes momentos se entrelazan: ya hay meditatio en la lectio y continuará en la oratio y la contemplatio. Para este trabajo paciente de escucha, los antiguos usaron imágenes naturales muy gráficas:

- La elaboración del néctar. El lector del texto bíblico es como una abeja que va de texto en texto sacando el néctar con el cual elaborar la miel divina. Así dice Nilo de Ancira: "Se puede comparar la letra simple de la Escritura inspirada de Dios con la celdilla de la cera. El Espíritu escondido en la letra será llamado miel en el sentido figurado" (cf. NiLo DE AncirA, Carta,1.264, a Calímaco; PL 70, 81). Cf. Prov 6,8; 24,13.

- El rumiar de las animales. Los padres latinos usaron para esta meditación paciente de la Palabra el término ruminatio, a semejanza de los animales que dan vueltas y vueltas a productos dificiles de digerir para convertirlos en alimentos que dan fuerza. Las dos imágenes suponen el trabajo, el esfuerzo, el silencio y la paciencia.

Ahora bien, el lector no debería caer en una especie de voluntarismo meditativo. El sentido siempre adviene como don, a semejanza de lo dicho en la parábola de la semilla que crece por si sola ("La tierra va produciendo fruto sola: primero los tallos, luego la espiga, después el grano": Mc 4,28). La meditatio es, en el fondo, una espera paciente de la Palabra divina, como el agricultor que hace todo lo que está en su mano para después esperar pacientemente que la semilla vaya creciendo y dé su fruto. Decía san Isidoro de Sevilla: "Cuanto más asiduo se es en la lectura de la Escritura, más rica es la inteligencia que se alcanza. Es lo mismo que sucede con la tierra: cuando más se la cultiva, más produce" (Libro tercero de las Sentencias, 9.2; PL 83, 681). 
La meditatio implica, en fin, el proceso por el que el lector no solo confronta un texto de la Escritura con otro, sino su propia vida con el texto. ¿En qué me parezco yo al pecador David, al soñador José, al pusilánime Gedeón? ¿En qué se parece nuestro mundo, lacerado por el hambre y la violencia, al reino de Dios? La lectio divina es asumir las preguntas de la historia y responderla desde la cruz de Cristo. El lector se somete al juicio del texto y descubre la verdad, a un tiempo dolorosa y luminosa, sobre su vida y sobre el futuro de la humanidad. Ahora reconoce, por tanto, que ha buscado comprender el texto porque así se comprende mejor a sí mismo. Cuanto más se reconoce el lector en el texto bíblico, más descubre su verdadera identidad, su filiación divina. Y es que se está produciendo el maravilloso proceso por el que el creyente asiste al paso de la lectura de la Palabra al encuentro con el que la dice, el mismo Señor.

Antes de continuar es adecuado notar que hoy hay una tendencia a identificar la lectura y meditación de la Escritura como una actividad solitaria y meramente individual. Pero la lectio divina de los monasterios era una actividad eminentemente comunitaria, relacionada con la schola catequética, con la collatio monástica y con la celebración litúrgica. Así dice san Gregorio Magno: "Sé que, generalmente, muchas cosas que sólo no pude entender en la Sagrada Escritura, las entendí junto a mis hermanos.... Por tanto, resulta que, con el favor de Dios, el entender crece y el orgullo disminuye al aprender, por causa vuestra, lo que entre vosotros enseño; porque, confieso la verdad, generalmente con vosotros oigo lo que digo" (san GREGorio MAGNo, Hom. sobre Ezequiel, 2.2.1; CCL 142, 225; BAC 170, p. 406). Por tanto, es saludable la lectio divina comunitaria, donde haya tiempos de lectura individual y tiempos de compartir aquello que leemos, meditamos y oramos, siempre teniendo en cuenta que la Palabra alcanza su culmen en la proclamación litúrgica. Al menos, el lector solitario debe tener en cuenta a toda la Iglesia y a la humanidad sufriente cuando se acerca al texto inspirado.

En este contexto eclesial de la lectura de la Palabra, también es adecuado reparar en que los antiguos usaron un modo particular de leer la Escritura que era meditarla a la luz de la vida de los santos: "viva lectio est vita bonorum" (san GREgorio MAGno, 
Comentario moral a Job, 24.16; CCL 143B, 1199). Así también ha dicho recientemente el papa Benedicto XVI: "La interpretación más profunda de la Escritura proviene precisamente de los que se han dejado plasmar por la Palabra de Dios a través de la escucha, la lectura y la meditación asidua... Cada santo es como un rayo de luz que sale de la Palabra de Dios" (Verbum Domini, 48). ¿Quién nos enseña mejor a creer sino Abrahán? ¿Quién instruye mejor a escuchar sino María? ¿Quién ejemplifica mejor aquello de "orar sin descanso" sino san Benito? ¿Cómo entender las bienaventuranzas sino verlas plasmadas en Cristo? "El Espíritu Santo, que ha inspirado a los autores sagrados, es el mismo que anima a los santos a dar la vida por el Evangelio. Acudir a su escuela es una vía segura para emprender una hermenéutica viva y eficaz de la Palabra de Dios" (Verbum Domini, 49).

Damos un paso adelante y pasamos a la oratio. Ahora el lector pasa de la escucha a la respuesta. El texto ha provocado en él la alabanza, la gratitud, el perdón, la lamentación, la súplica. E1 mismo texto puede prestar el motivo o las palabras de su oración, como hizo Jesús orando tantas veces con los salmos (Sal 22,2 en Mc 15,34; Sal 31,6 en Lc 23,46; etc.). ¿Qué mejor que usar las palabras divinas para dirigirse a Dios? Pero oratio en latín no significa solo "oración" sino también "discurso". El "concepto" que ha sido rumiado en el corazón a través de la lectio no puede permanecer un minuto más en el interior y se convierte en pronunciamiento, canto o predicación: "De lo que rebosa el corazón habla la boca" (Mt 12,34).

Se llega poco a poco al culmen del proceso, pasamos de la oratio a la contemplatio, donde las preguntas dejan paso a la alegría por la presencia de Dios. El lector orante pasa de meditar qué dice Dios a gozar de que Él le diga algo. Contemplar es dejarse abrazar por la Palabra. El orante se abandona en Dios y experimenta cierta pasividad. Dios se convierte en el protagonista de la oración. Ahora bien, es preciso reconocer que no siempre, ni siquiera las más de las veces, el orante alcanza la contemplación. Ninguna gracia divina se recibe por necesidad. La experiencia de la humillación del que no ha sacado nada en claro tras emplearse a fondo con un texto es también camino pedagógico de crecimiento y santidad. Son pertinentes, en tal caso, las palabras del diácono sirio San 
Efrén: "Lo que has recibido y conseguido es tu parte, lo que ha quedado es tu herencia. Lo que, por tu debilidad, no puedes recibir en un determinado momento, lo podrás recibir en otra ocasión, si perseveras. Ni te esfuerces avaramente por tomar de un solo sorbo lo que no puede ser sorbido de una vez, ni desistas por pereza de lo que puedes ir tomando poco a poco" (Comentario sobre el Diatésaron, 1,18-19; SC 121, 52-53).

Por otro lado, es preciso precaver contra otro malentendido. A veces se concibe la contemplación como un éxtasis místico inalcanzable, una especie de quietismo espiritualista. Pero los espiritualismos no son buenos para leer la Escritura, tan anclada siempre en la realidad histórica. La contemplación consiste, más bien, en la total aceptación, con corazón indiviso, de la voluntad de Dios. Esta voluntad afecta a la historia personal, eclesial y global. En la contemplación el orante asume gozosamente el proyecto de Dios hasta clamar con el salmista: "Aquí estoy - como está escrito en mi libro- para hacer tu voluntad. Dios mío, lo quiero, y llevo tu ley en las entrañas" (Sal 40,8-9; cf. Heb 10,5-7). En conclusión, la contemplación es el don divino por el que el orante se abre a la verdad de la historia de la salvación, tanto propia como universal, y comprende su unidad. Todo encuentra el gozo de la unidad: el Antiguo y el Nuevo Testamento, el pasado de la historia de la salvación y el presente de la historia de la Iglesia, el cielo y la tierra, el hombre y Dios.

Finalmente, la contemplación conduce a la actio, la encarnación de la Palabra, a que "Cristo tome forma en nosotros" (Gál 4,19). Aquel que ha atisbado y acogido la voluntad de Dios, se pregunta qué conversión de la vida y del corazón le pide el Señor, cómo puede y deber transformar nuestro mundo. El que ha contemplado la luz se convierte en luz para sus hermanos (cf. Mt 5,15). Así recomienda Benedicto XVI: "La lectio divina no termina su proceso hasta que no se llega a la acción (actio), que mueve la vida del creyente a convertirse en don para los demás por la caridad" (Verbum Domini,87). Por eso, como exhorta el Maestro a los discípulos en la transfiguración, el lector orante debe superar la tentación de permanecer en el monte ("Maestro, iqué bien se está aquí!»: Mc 9,5) y bajar al llano para enfangarse en la tarea del Reino. 
Comenzamos con la cita de san Gregorio Magno ("las palabras divinas crecen con el que las lee») sobre la dinámica de crecimiento constante tanto de lector como de la Escritura. Acabamos con otra cita del papa santo, una de las cimas de todos los tiempos en la reflexión sobre la lectura espiritual de la Escritura, en la que también se alude a esta vorágine de altura: "La Escritura se abaja al usar nuestras pobres expresiones para hacernos subir poco a poco, como por escalones, desde lo que vemos cercano a nosotros y a nuestro alcance, hacia las cimas más altas de Él» (san GrEGorio Magno, Comentario moral a Job, 20.63; CCL 143A, 1050). Así pues, la lectio divina siempre permanece inacabada, propone un itinerario místico de ascenso solo culminado en la pascua final. De la lectura al encuentro, de la lectura del texto al diálogo con la Palabra, ese es el camino a recorrer.
\end{abstract}

